\title{
Prediction Method for the Radial Runout of Inner Ring in Cylindrical Roller Bearings
}

\author{
Yongjian Yu, ${ }^{1}$ Guoding Chen, ${ }^{1}$ Jishun $\mathrm{Li}^{2}{ }^{2}$ Yujun Xue, ${ }^{3,4}$ and Bitao Pang ${ }^{4}$ \\ ${ }^{1}$ School of Mechanical Engineering, Northwestern Polytechnical University, Xian, China \\ ${ }^{2}$ Henan Key Laboratory for Machinery Design and Transmission System, Henan University of Science and Technology, Luoyang, China \\ ${ }^{3}$ School of Mechatronics Engineering, Henan University of Science and Technology, Luoyang, China \\ ${ }^{4}$ Luoyang LYC Bearings Co., Ltd., State Key Laboratory of Aviation Precision Bearings, Luoyang, China
}

Correspondence should be addressed to Jishun Li; li_jishun@163.com

Received 21 January 2017; Revised 3 April 2017; Accepted 12 April 2017; Published 31 May 2017

Academic Editor: Zhen-Lai Han

Copyright (c) 2017 Yongjian Yu et al. This is an open access article distributed under the Creative Commons Attribution License, which permits unrestricted use, distribution, and reproduction in any medium, provided the original work is properly cited.

\begin{abstract}
The motion error of assembled bearing depends on the geometric profile of bearing components. Therefore, it is crucial to establish the relationship between geometric error of bearing components and motion error of assembled bearing, which contributes to improving the rotational accuracy of assembled bearing in the design and machining of the bearing. The main purpose of this research is to propose an accurate method for predicting the radial runout of inner ring based on the geometrical constraint model of cylindrical roller bearings. In the geometrical constraint model, dimension and form errors in the inner raceway, the outer raceway, and rollers are considered, and the change of contact positions between the raceways and rollers caused by geometric errors of bearing components is taken into account. This method could predict the radial runout of inner ring after bearing components with geometric error are assembled. In order to testify the validity of the proposed prediction method, two particular cases in which the profiles of the inner raceway are circle and ellipse are selected, and the analysis algorithms for the radial runout of inner ring are derived. Two analytical results obtained from the analysis algorithms validate accuracy and effectiveness of the proposed prediction method.
\end{abstract}

\section{Introduction}

Rolling bearing is mainly used to support shafting, keeping motion accuracy of shafts. Rotational accuracy of assembled bearing, as an important parameter to measure dynamic performance of the roller bearing, often directly determines the accuracy of mechanical systems $[1,2]$. Geometric error is always present in manufactured bearing components, which is one of the important factors that cause the motion error of assembled bearing. Therefore, it is significant to establish the relationship between geometric errors of bearing components and rotational accuracy of assembled bearing.

At present, for the rotational accuracy of ball bearings, most researchers focus on shaft centerline orbit and nonrepetitive runout of ball bearings. Okamoto et al. [3] developed a model to predict shaft centerline orbit of ball bearings based on form error of the outer raceway. Noguchi et al. [4-7] presented a computational model about nonrepetitive runout of ball bearings considering form error of the inner and outer raceways. Tada [8] established a three-dimensional model to calculate nonrepetitive runout of angular contact ball bearings based on the waviness of bearing components. Jang et al. [9] characterized the source of nonrepetitive runout (NRRO) of ball bearings and the transmission of NRRO from the ball bearing to the disk. Yang et al. [10-12] established a mathematical model and a five-degree-of-freedom model to research the influences of geometric error on the NRRO of an angular contact ball bearing. Chen et al. $[13,14]$ developed a one-dimensional mathematical model with algebraic equation considering roundness error of the raceways and diameter error of the rollers. The influence of diameter differences among the rollers on the load performance in a cylindrical roller bearing was investigated. Liu et al. [15] developed a computational 
model about nonrepetitive runout of high-speed angular contact ball bearings based on five-freedom quasi-statics method. Li and Mao [16] developed a five-freedom static model for nonrepetitive runout of deep groove ball bearings. Bhateja and Pine [17] established a prediction model for rotational accuracy of hollow roller bearings considering dimension difference of the rollers. Wang [18] presented a model to predict geometric accuracy of a cylindrical roller bearing considering form error of the inner or outer raceway. In previous research, the effect of roundness error of the inner and outer raceways on rotational accuracy of cylindrical roller bearings was researched, respectively. A computational model for the radial runout of inner ring based on form error of the inner raceway was established [19], and a computational model for the radial runout of outer ring considering form error of the outer raceway was developed $[20,21]$.

In these current researches, the methods for rotational accuracy of cylindrical roller bearings were proposed considering form error of the inner raceway or the outer raceway or dimension error of the rollers, in which it was assumed that the contact positions between the rollers and the raceways do not change. However, the rotational accuracy of assembled bearing should result from the interaction among geometric errors of the inner raceway, the outer raceway, and the rollers. Meanwhile, the contact positions between the rollers and the raceways change with geometric errors of bearing components; thus the influence of the whole profiles of bearing components on the rotational accuracy of the bearing could be reflected perfectly and accurately. Therefore, it is very necessary to carry out some further researches to develop a method to accurately predict the rotational accuracy of cylindrical roller bearings. For this purpose, this research proposes a prediction method for the radial runout of inner ring in cylindrical roller bearings based on the geometrical constraint model of cylindrical roller bearings. The geometrical constraint model considers the change of contact positions between the raceways and rollers and the dimension and form errors in the raceways and rollers. The proposed method could accurately predict the radial runout of inner ring under given or known dimension and form errors of the inner raceway, the outer raceway, and rollers. This prediction method could be used to research the influences of geometric errors of bearing components and their coupling effect on the rotational accuracy of assembled bearing, thus establishing the relationship between geometric errors of bearing components and the radial runout of inner ring in cylindrical roller bearings.

\section{Basic Assumptions}

According to the international standards for rotational accuracy measurement of a rolling bearing, when the radial runout of a rolling bearing is measured, a ring is fixed, and another ring is rotating at very slow speed and its vertical displacement is measured as its radial runout value every rotational angle of the ring. To make the raceways contact with the rollers, a small measuring load is applied to the bearing, which can not cause obvious elastic deformation of bearing components. According to the above measurement operating conditions, a prediction method for the radial runout of inner ring in cylindrical roller bearings is presented, which is based on the following assumptions:

(1) There are no axial geometric errors in the raceways and rollers.

(2) The rollers are distributed in the circumferential direction uniformly, without considering the influence of cage.

(3) There is no slip at the rolling element-raceway contact.

(4) Lubrication in the bearing is not taken into account.

\section{Characterization Method for Geometric Error of Bearing Components}

As for the above assumptions, only dimension and form errors in the raceways and rollers are taken into account. The geometric error of bearing components can be expressed with addition of the dimension and roundness errors in the raceways and rollers. Hereinto, the roundness error item is described by the Fourier series in a polar coordinates system.

$$
\Delta S(\theta)=\Delta r+\Delta R=\Delta r+\sum_{m=1}^{\infty} C_{m} \cos \left(m \theta+\varphi_{m}\right)
$$

where $\Delta S$ is the geometric error of bearing components. $\Delta r$ is the dimension error of bearing components. $\Delta R$ is the roundness error of bearing components. $m$ is the order of a harmonic component. $\theta$ is the polar angle. $C$ is the amplitude of a harmonic component. $\varphi$ is the phase angle of a harmonic component.

The geometric error of bearing components can be given arbitrarily. However, the geometric error of bearing components is unknown for manufactured bearing components, which needs to be obtained through experiments. The dimension errors of different circumferential positions are measured by the bearing comparator. The dimension error of bearing components is equal to the average value of dimension errors of different circumferential positions. The roundness error of manufactured bearing components is expressed by Fourier series. In order to get harmonic orders, amplitudes, and phase angles of roundness error, the roundness instrument is used to collect the data of running surface profile of manufactured bearing components. These parameters are obtained with Fourier transformation of the data of running surface profile, and thus the roundness error of bearing components is restructured.

\section{Geometrical Constraint Model of Cylindrical Roller Bearings}

Due to geometric error of bearing components, the raceways and rollers shapes are noncircular profile, as shown in Figure 1. A fixed global Cartesian coordinate system $(X, Y)$ is set up at the center of the bearing with the origin $O$ coinciding with the center of the outer raceway. Also, a moving Cartesian 


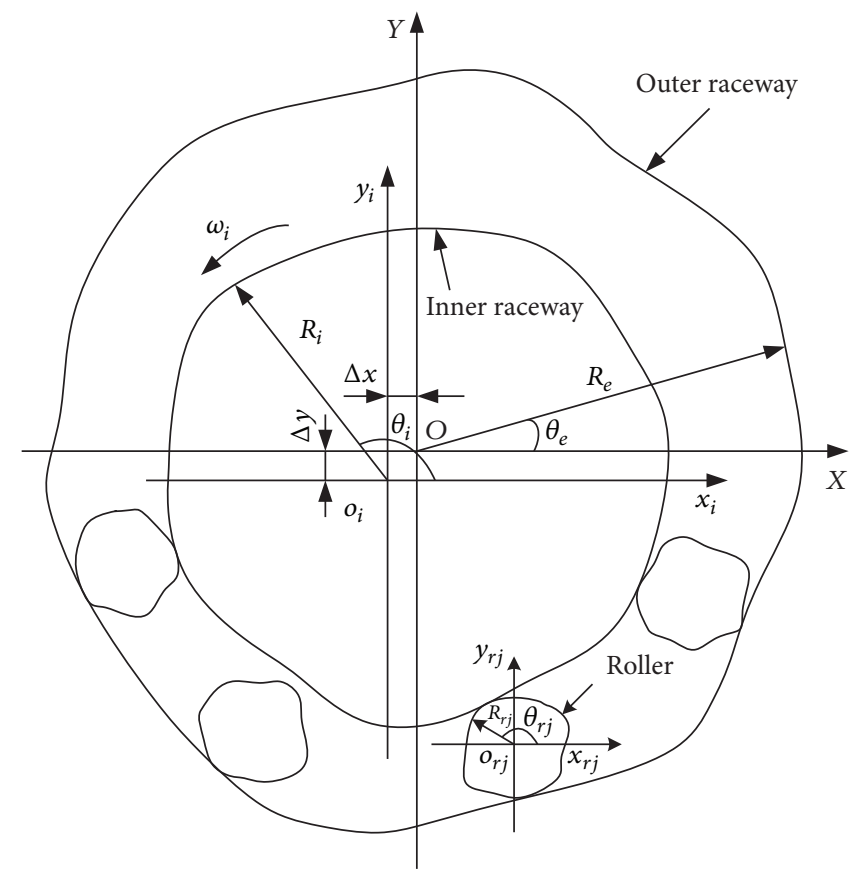

FIGURE 1: Geometrical constraint model of cylindrical roller bearings.

coordinate system $\left(x_{i}, y_{i}\right)$ is fixed to the center of the inner raceway, which translates with the inner ring and is always parallel to the global coordinate $(X, Y)$, respectively. Another moving Cartesian coordinate system $\left(x_{r j}, y_{r j}\right)$ is fixed to the center of the $j$ th roller, which translates with the $j$ th roller and is always parallel to the global coordinate $(X, Y)$, respectively. The inner ring rotates, and the outer ring is fixed. When a small measuring load is applied vertically downward to the inner ring, the inner ring moves down and eventually reaches a stable state. In that case, the horizontal displacement of the center $o_{i}$ of the inner raceway is $\Delta x$, and the vertical displacement of the center $o_{i}$ of the inner raceway is $\Delta y$; meanwhile it is the radial runout value of inner ring, too.

The inner ring rotates anticlockwise, and rollers revolve anticlockwise; in the meantime rollers spin clockwise. The rotation angle of the inner ring is $\alpha$. The autorotation and orbital angle of rollers are calculated by (2) and (3), respectively.

$$
\begin{aligned}
& \gamma_{1}=\frac{\left(d_{i}+d_{e}\right)^{2}-4 D_{w}^{2}}{\left(d_{i}+d_{e}\right) D_{w}} \alpha, \\
& \gamma_{2}=0.5 \alpha\left(1-\frac{2 D_{w}}{\left(d_{i}+d_{e}\right)}\right),
\end{aligned}
$$

where $\gamma_{1}$ and $\gamma_{2}$ is the autorotation and orbital angle of rollers, respectively. $D_{w}$ is the roller diameter. $d_{i}$ and $d_{e}$ are the diameter of inner raceway and outer raceway, respectively.
The inner raceway, outer raceway, and the $j$ th roller radii $R_{i}, R_{e}$, and $R_{r j}$ at the different azimuth angles corresponding with coordinate systems $x_{i} o_{i} y_{i}, X O Y$, and $x_{r j} o_{r j} y_{r j}$ are expressed by

$$
\begin{aligned}
R_{i}\left(\theta_{i}\right) & =\frac{d_{i}}{2}+\frac{\Delta d_{i}}{2}+\Delta R_{i}, \\
R_{e}\left(\theta_{e}\right) & =\frac{d_{e}}{2}+\frac{\Delta d_{e}}{2}+\Delta R_{e}, \\
R_{r j}\left(\theta_{r j}\right) & =\frac{D_{w}}{2}+\frac{\Delta D_{j}}{2}+\Delta R_{r j},
\end{aligned}
$$

where $\Delta d_{i}, \Delta d_{e}$, and $\Delta D$ are the diameter error of the inner raceway, the outer raceway, and rollers, respectively, and the subscript $j$ denotes the roller number $(j=1,2, \ldots, Z) . \Delta R_{i}$, $\Delta R_{e}$, and $\Delta R_{r}$ are the roundness error of the inner raceway, the outer raceway, and rollers, which are expressed by (5) (7), respectively.

$$
\begin{aligned}
\Delta R_{i}\left(\theta_{i}\right) & =\sum_{m=1}^{\infty} C_{i m} \cos \left(m\left(\theta_{i}-\alpha\right)+\varphi_{i m}\right), \\
\Delta R_{e}\left(\theta_{e}\right) & =\sum_{m=1}^{\infty} C_{e m} \cos \left(m \theta_{e}+\varphi_{e m}\right), \\
\Delta R_{r j}\left(\theta_{r j}\right) & =\sum_{m=1}^{\infty} C_{r j m} \cos \left(m\left(\theta_{r j}+\gamma_{1}\right)+\varphi_{r j m}\right),
\end{aligned}
$$

where $C_{i}$ and $C_{e}$ are the amplitude of harmonic components. $\varphi_{i}, \varphi_{e}$, and $\varphi_{r}$ are the phase angles of harmonic components. 


\section{Prediction Method for the Radial Runout of Inner Ring}

It is assumed that the inner ring rotates and the outer ring is fixed. The position of the inner ring varies with the inner ring rotating. When the inner ring rotates an angle, due to the gravity and the geometrical constraint of bearing components, the inner ring moves in the vertical and horizontal directions until it contacts with the partial rollers at the bottom of the bearing and reaches a stable position, which is unique. In order to obtain the stable position of the inner ring, a prediction method for the radial runout of inner ring is presented. Its calculation process is as follows: The first step is to calculate coordinates of the center of each roller at the bottom of the bearing. The rollers at the bottom of the bearing purely roll to a new position with the inner ring rotating. Each roller is moved along the radial direction with a given step, until it contacts with the outer raceway. The coordinates of the center of each roller are calculated. The second step is to obtain the contact statuses of the inner raceway in different positions of the inner ring. The inner ring moves both vertically and horizontally at a given step in a certain range, and the position relation (contact, separation, interference) between the inner raceway and each roller at the bottom of the bearing is obtained in different positions, and the number and position angle of rollers which contact with the inner raceway are obtained. Thus, the contact statuses of the inner raceway are obtained in different positions. The third step is to obtain the coordinates of the center of the inner raceway. According to the contact statuses of the inner raceway in the different positions of the inner ring, the stable position of the inner ring where the inner ring is stable is distinguished by the criterion for stable contact between the inner raceway and rollers from some positions of the inner ring; thus the coordinates of the center of the inner ring are obtained. Therefore, the radial runout value of inner ring is obtained every rotation angle of the inner ring. Hereinto, the difference between the maximal radial runout value and the minimal radial runout value is the radial runout of inner ring.

5.1. Calculation of Coordinates of the Center of Rollers. To obtain the coordinates of the center of rollers at the bottom of the bearing when the rollers contact with the outer raceway, it is assumed that a roller at the bottom of the bearing is moved along the radial direction at a given step until it contacts with the outer raceway; thus the distance between the center of the roller and the center of the outer raceway is obtained. According to the geometric relationship among bearing components, the coordinates of the center of the roller are calculated through the distance. Hereinto, the key problem is to calculate the shortest distance between the outer raceway and the surface of the roller when the roller is moved to a position, thus determining whether the roller contacts with the outer raceway. For this purpose, a calculation method of the shortest distance is proposed.

The inner ring rotates an angle $\alpha$, and the $j$ th roller is moved to a position with the distance $D_{e j}$ between the center of the $j$ th roller and the center of the outer raceway. The geometric relationship between a roller and the outer raceway is shown in Figure 2. The distance between any point $A$ on the outer raceway and any point $B$ on the surface of the $j$ th roller is expressed by

$$
A B=A o_{r j}-B o_{r j}
$$

where $A o_{r j}$ is the distance between the center of the $j$ th roller and any point $A$ on the outer raceway, which is calculated by (9). $B o_{r j}$ is the radius of any point $B$ on the surface of the $j$ th roller when the $j$ th roller spins around its axis at an angle of $\gamma_{1}$, which is calculated by $(10)$.

$$
A o_{r j}=\sqrt{O A^{2}+O o_{r j}^{2}-2 O A \times O o_{r j} \cos \left(\Delta \theta_{e}\right)}
$$

where $O A$ is the radius of any point $A$ on the outer raceway, which is calculated by (11). Oo $o_{r j}$ is the distance between the center of the outer raceway and the center of the $j$ th roller, which is known, namely, $D_{e j} . \Delta \theta_{e}$ is the angle between any point $A$ on the outer raceway and the center of the $j$ th roller in the circumferential direction, $-\arcsin \left(D_{w} / d_{e}\right) \leq \Delta \theta_{e} \leq$ $\arcsin \left(D_{w} / d_{e}\right)$.

$$
\begin{aligned}
B o_{r j}= & R_{r j}\left(\theta_{B}\right) \\
= & \frac{D_{w}}{2}+\frac{\Delta D_{j}}{2} \\
& +\sum_{m=1}^{\infty} C_{r j m} \cos \left(m \theta_{B}+m \gamma_{1}+\varphi_{r j m}\right), \\
O A= & R_{e}\left(\theta_{A}\right) \\
= & \frac{d_{e}}{2}+\frac{\Delta d_{e}}{2}+\sum_{m=1}^{\infty} C_{e m} \cos \left(m \theta_{A}+\varphi_{e m}\right),
\end{aligned}
$$

where $\theta_{A}$ is the polar angle of any point $A$ on the outer raceway. $\theta_{B}$ is the polar angle of any point $B$ on the surface of the $j$ th roller, which is related to the location of the $j t h$ roller and $B$ point, as described in next paragraph.

When the $j$ th roller is located in the third quadrant and $B$ point is located above the line $\mathrm{Oo}_{r j}$, the geometric relationship between the $j$ th roller and the outer raceway is shown in Figure 2(a), $\theta_{B}=\phi_{e j}+\beta_{j}-\pi$; thereinto, $\phi_{e j}=\arccos \left(\left(A o_{r j}{ }^{2}+\right.\right.$ $\left.\left.O o_{r j}{ }^{2}-O A^{2}\right) /\left(2 A o_{r j} \times O o_{r j}\right)\right), \beta_{j}$ is the position angle of rollers, and $\beta_{j}=2 \pi(j-1) / Z+\gamma_{2}, Z$ is roller number. When the $j$ th roller is located in the third quadrant and $B$ point is located below the line $O o_{r j}$, the geometric relationship between the $j$ th roller and the outer raceway is shown in Figure 2(b), $\theta_{B}=\pi-\phi_{e j}+\beta_{j}$. When the $j$ th roller is located in the fourth quadrant and $B$ point is located above the line $O o_{r j}$, the geometric relationship between the $j$ th roller and the outer raceway is shown in Figure 2(c), $\theta_{B}=\beta_{j}-\pi-\phi_{e j}$. When the $j$ th roller is located in the fourth quadrant and $B$ point is located below the line $\mathrm{Oo}_{r j}$, the geometric relationship between the $j$ th roller and the outer raceway is shown in Figure 2(d), $\theta_{B}=\beta_{j}-\pi+\phi_{e j}$.

In (8), when the angle $\Delta \theta_{e}$ varies in a certain range, there is a point $A$ on the outer raceway and a point $B$ on surface of the $j$ th roller, which make the distance between point $A$ and 


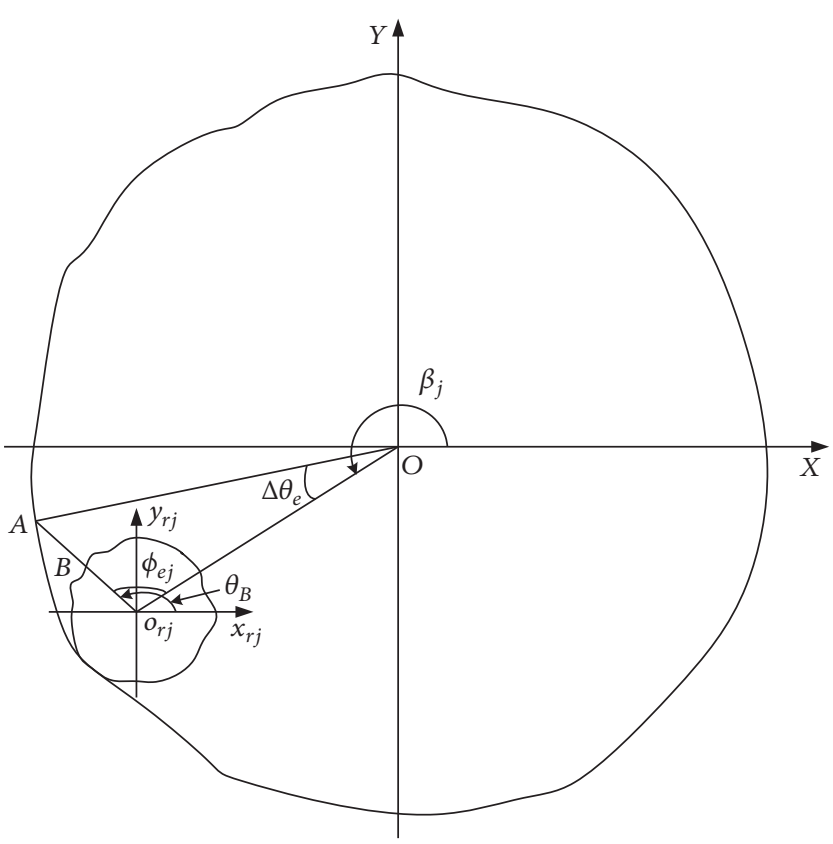

(a)

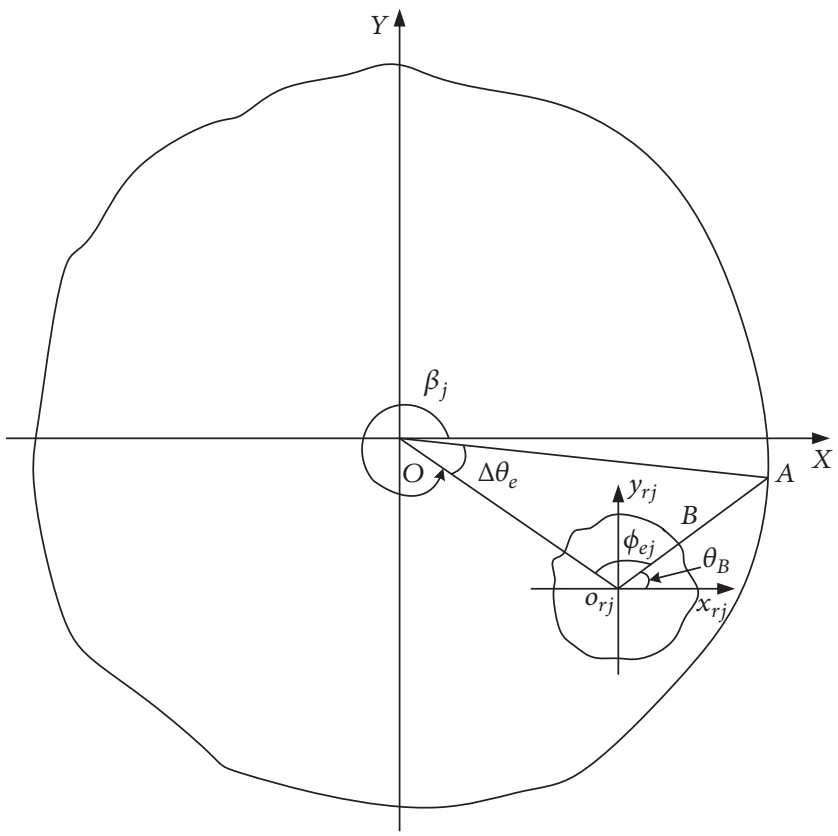

(c)

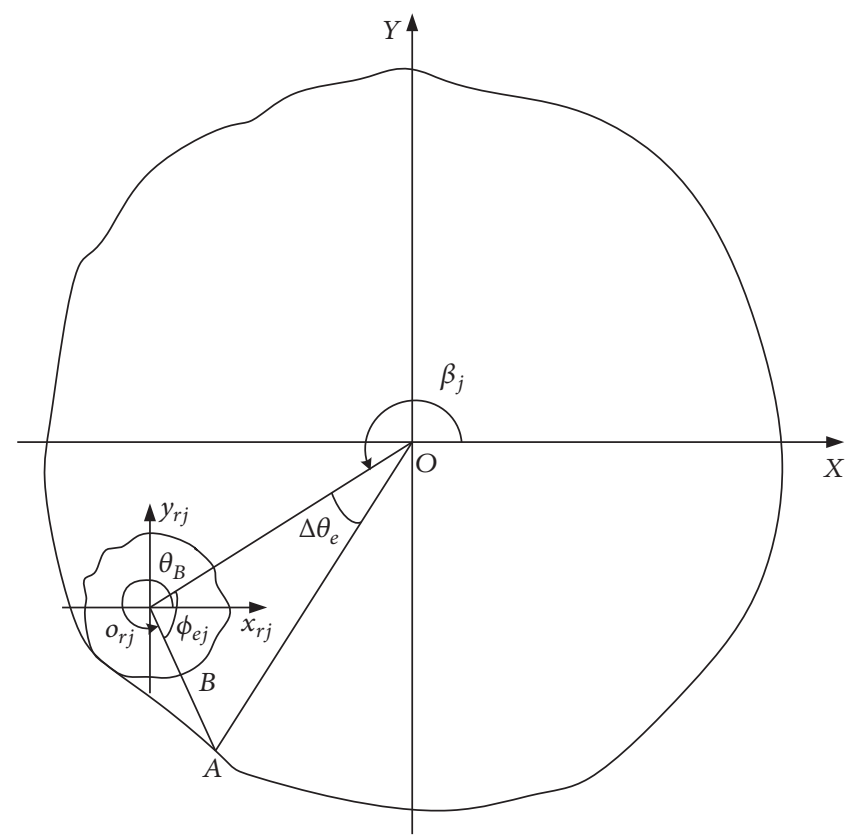

(b)

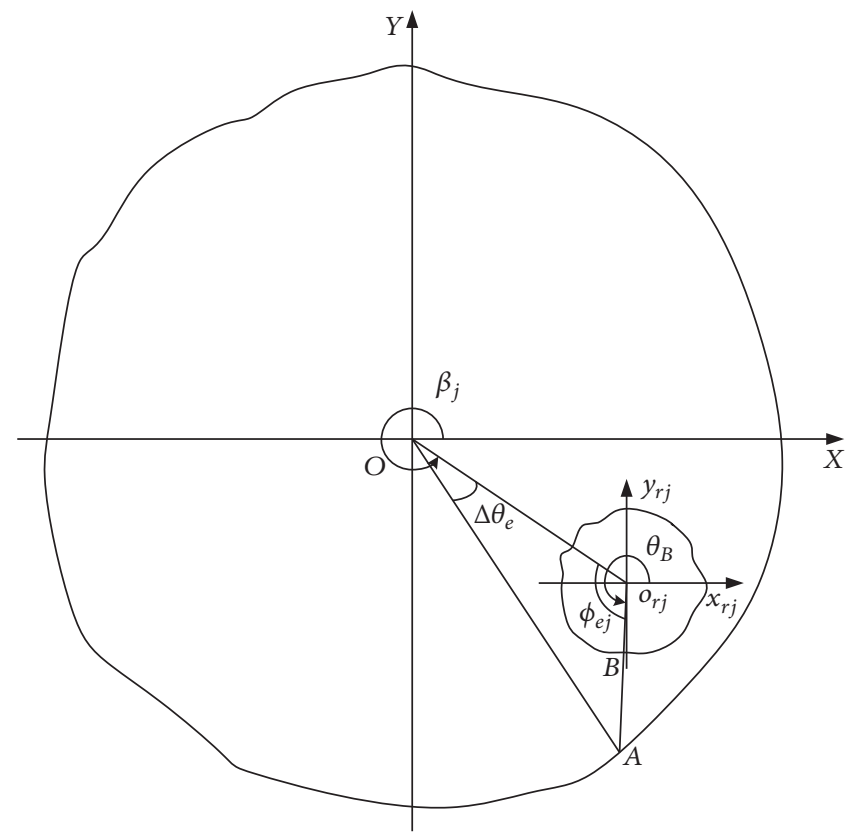

(d)

FIGURE 2: Geometric relationship between a roller and the outer raceway.

point $B$ reach a minimum value, namely, the shortest distance between the outer raceway and the surface of the $j$ th roller.

When the shortest distance between the outer raceway and surface of the $j$ th roller is more than given tolerance, the $j$ th roller does not contact with the outer raceway, continuing to move the $j$ th roller along the radial direction. When the absolute value of the shortest distance is less than given tolerance, the $j$ th roller contacts with the outer raceway. Thus, the distance $D_{e j}$ between the center of the $j$ th roller and the center of the outer raceway is obtained. According to the geometric relationship among bearing components, the coordinates of the center of the $j$ th roller are calculated by (12). In the same way, the coordinates of the center of each roller at the bottom of the bearing are calculated.

$$
\begin{aligned}
& X_{r j}=D_{e j} \cos \left(\beta_{j}\right), \\
& Y_{r j}=D_{e j} \sin \left(\beta_{j}\right) .
\end{aligned}
$$




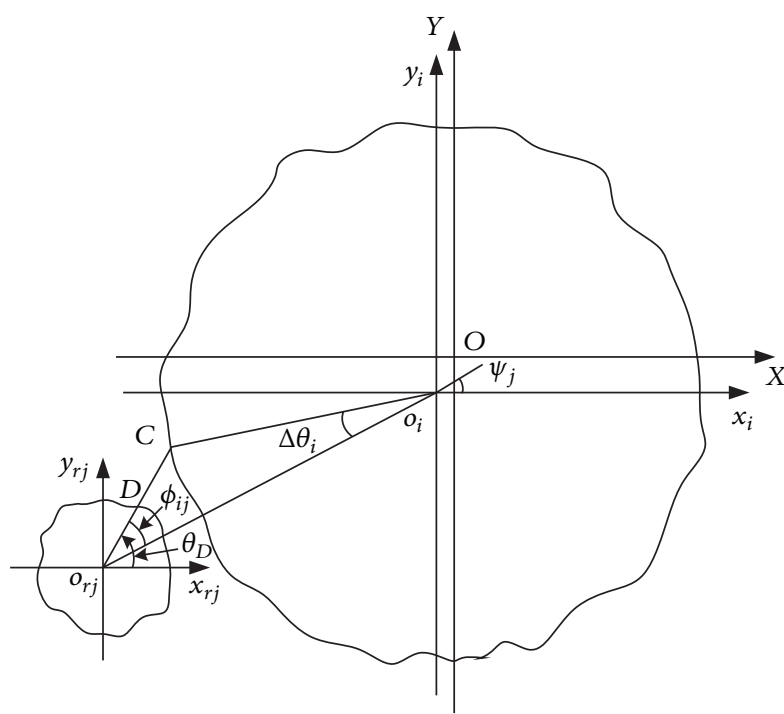

(a)

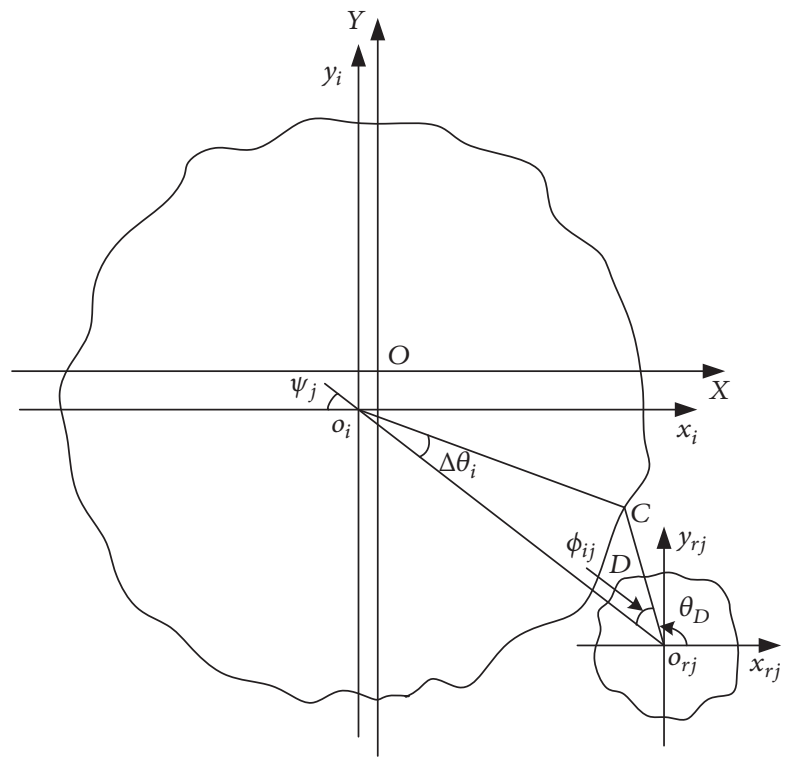

(c)

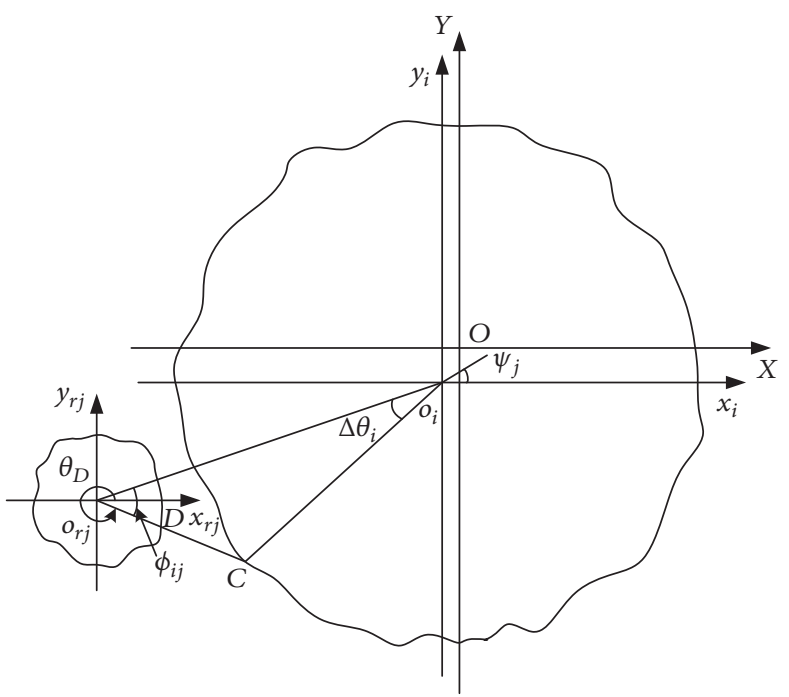

(b)

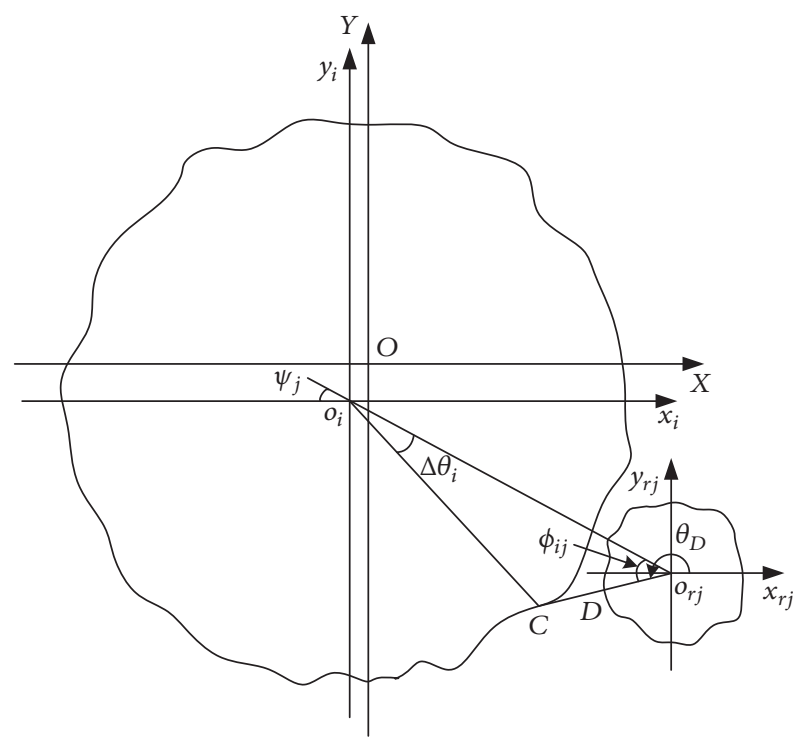

(d)

FIGURE 3: Geometric relationship between a roller and the inner raceway.

5.2. Contact Statuses of the Inner Raceway in Different Positions. When the inner ring is located in a position, the contact status of the inner raceway depends on the position relationship (contact, separation, and interference) between the inner raceway and each roller at the bottom of the bearing. In order to obtain the position relationship between the inner raceway and each roller, a calculation method for the shortest distance between the surface of a roller and the inner raceway is proposed.

When the inner ring rotates an angle $\alpha$, and it is shifted to a position, the geometric relationship between the $j$ th roller and the inner raceway is shown in Figure 3. The distance between any point $C$ on the inner raceway and any point $D$ on the surface of the $j$ th roller is expressed by

$$
C D=C o_{r j}-D o_{r j},
$$

where $C o_{r j}$ is the distance between any point $C$ on the inner raceway and the center of the $j$ th roller, which is calculated by (14). $D o_{r j}$ is the radius of any point $D$ on the surface of the $j$ th roller when the $j$ th roller spins around its axis at an angle of $\gamma_{1}$, which is given by (15).

$$
C o_{r j}=\sqrt{C o_{i}^{2}+o_{i} o_{r j}^{2}-2 C o_{i} \times o_{i} o_{r j} \cos \left(\Delta \theta_{i}\right)},
$$

where $\mathrm{Co}_{i}$ is the radius of $C$ point on the inner raceway, which is expressed by (16). $o_{i} o_{r j}$ is the distance between the center of the inner raceway and the center of the $j$ th roller. $\Delta \theta_{i}$ is the angle between any point $C$ on the inner raceway and 
the center of the $j$ th roller in the circumferential direction, $-\arcsin \left(D_{w} / d_{i}\right) \leq \Delta \theta_{i} \leq \arcsin \left(D_{w} / d_{i}\right)$.

$$
\begin{aligned}
D o_{r j}= & R_{r j}\left(\theta_{D}\right) \\
= & \frac{D_{w}}{2}+\frac{\Delta D_{j}}{2} \\
& +\sum_{m=1}^{\infty} A_{r j m} \sin \left(m \theta_{D}+m \gamma_{1}+\varphi_{r j m}\right), \\
C o_{i}= & R_{i}\left(\theta_{C}\right) \\
= & \frac{d_{i}}{2}+\frac{\Delta d_{i}}{2}+\sum_{m=1}^{\infty} C_{i m} \sin \left(m \theta_{C}-m \alpha+\varphi_{i m}\right),
\end{aligned}
$$

where $\theta_{C}$ is the polar angle of any point $C$ on the inner raceway. $\theta_{D}$ is the polar angle of any point $D$ on the surface of the $j$ th roller, which is related to the location of the $j$ th roller and $D$ point, as described in next paragraph.

When the $j$ th roller is located in the third quadrant and $D$ point is located above the line $o_{i} o_{r j}$, the geometric relationship between the $j$ th roller and the inner raceway is shown in Figure 3(a), $\theta_{D}=\psi_{j}+\phi_{i j}$; thereinto, $\phi_{i j}=\arccos \left(\left(\mathrm{Co}_{r j}{ }^{2}+\right.\right.$ $\left.\left.o_{i} o_{r j}{ }^{2}-C o_{i}{ }^{2}\right) /\left(2 C o_{r j} \times o_{i} o_{r j}\right)\right), \psi_{j}=\arctan \left(\left|Y_{i}-Y_{r j}\right| /\left|X_{i}-X_{r j}\right|\right)$, and $X_{i}$ and $Y_{i}$ are the coordinates of the center of the inner raceway. When the $j$ th roller is located in the third quadrant and $D$ point is located below the line $o_{i} o_{r j}$, the geometric relationship between the inner raceway and the $j$ th roller is shown in Figure $3(\mathrm{~b}), \theta_{D}=\psi_{j}+2 \pi-\phi_{i j}$. When the $j$ th roller is located in the fourth quadrant and $D$ point is located above the line $o_{i} o_{r j}$, the geometric relationship between the inner raceway and the $j$ th roller is shown in Figure 3(c), $\theta_{D}=\pi-\psi_{j}-\phi_{i j}$. When the $j$ th roller is located in the fourth quadrant and $D$ point is located below the line $o_{i} o_{r j}$, the geometric relationship between the inner raceway and the $j$ th roller is shown in Figure 3(d), $\theta_{D}=\pi-\psi_{j}+\phi_{i j}$.

In (13), when the angle $\Delta \theta_{i}$ varies in a certain range, there is a point $C$ on the inner raceway and a point $D$ on the surface of the $j$ th roller, which make the distance between point $C$ and point $D$ reach a minimum value, namely, the shortest distance between the inner raceway and the surface of the $j$ th roller. When the shortest distance is more than given tolerance, the $j$ th roller is separate from the inner raceway. When the absolute value of the shortest distance is less than given tolerance, the $j$ th roller contacts with the inner raceway. When the shortest distance is less than negative given tolerance, there is interference between the $j$ th roller and the inner raceway. Therefore, the position relationship between the $j$ th roller and the inner raceway is obtained.

In the same way, the position relationship between the inner raceway and each roller at the bottom of the bearing is obtained, and the number and position angle of rollers which contact with the inner raceway are obtained. Therefore, the contact status of the inner raceway is obtained when the inner ring is located in a position. The inner ring is moved to a new position, and so on; the contact statuses of the inner raceway are obtained in different positions of the inner ring.

5.3. Coordinates of the Center of the Inner Raceway. In order to obtain the stable position of the inner ring from different positions when the inner ring rotates an angle $\alpha$, according to the conditions that the stable position of the inner ring satisfies, the criterion for stable contact between the inner raceway and rollers is presented as follows:

(1) Noninterference between the inner raceway and rollers: To obtain the stable position of the inner ring, different positions of the inner ring are given. When the inner ring is located in some positions, there is interference between the inner raceway and rollers. Obviously, there is no interference among bearing components when the inner ring is located in the stable position.

(2) On any side of $y$-axis, there is at least one roller contacting with the inner raceway. Due to the gravity and the measuring load, when one roller contacts with the inner raceway, the inner ring is not stable. When two rollers are located on one side of $y$-axis, the inner ring is not stable, too. When there is at least one roller contacting with the inner raceway on each side of $y$-axis, the inner ring is stable.

(3) The angle $\alpha_{1}$ between the negative half-axis of $y$-axis and the angular bisector of the angle between the leftmost and rightmost roller which contact with the inner raceway is the smallest. When the angle $\alpha_{1}$ is getting smaller, the center of the inner ring is getting closer to the $y$-axis and the potential energy of the inner ring is getting smaller. There are many positions of the inner ring which meet the above two conditions. In these positions of the inner ring, the inner ring is stable in this position where the angle $\alpha_{1}$ is the smallest. Two positions of the inner ring are shown in Figure 4. The angle $\alpha_{1}$ is less in the first position than in the second position. Therefore, the first position is the stable position of the inner ring.

According to the contact statuses of the inner raceway in different positions, the stable position of the inner ring is discriminated from some positions by the criterion for stable contact between the inner raceway and rollers. Thus, the coordinates of the center of the inner raceway are obtained when the inner ring rotates an angle $\alpha$. And so on, the coordinates of the center of the inner raceway are obtained every rotation angle of the inner ring.

\section{Verification of the Proposed Prediction Method}

The proposed prediction method is verified through two particular cases in which the profiles of the inner raceway are circle and ellipse. For two particular cases, the motion error of the bearing can be derived theoretically. The prediction results obtained from the proposed prediction method are compared with the analytical results calculated by the derived analysis algorithms for motion error of the bearing. Main parameters of a cylindrical roller bearing with code NU209 is as shown in Table 1.

\subsection{Verification of the Prediction Method with Inner Raceway Profile for Circle}

6.1.1. Analysis Algorithm for the Radial Runout of Inner Ring with Inner Raceway Profile for Circle. There is no geometric 


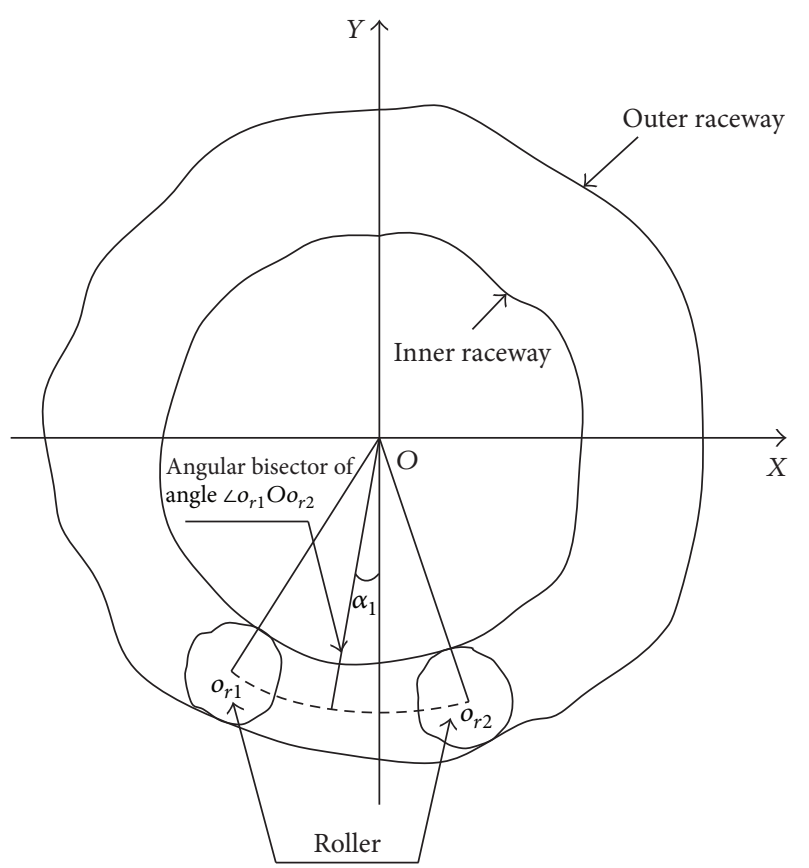

(a) The first contact status of the inner raceway

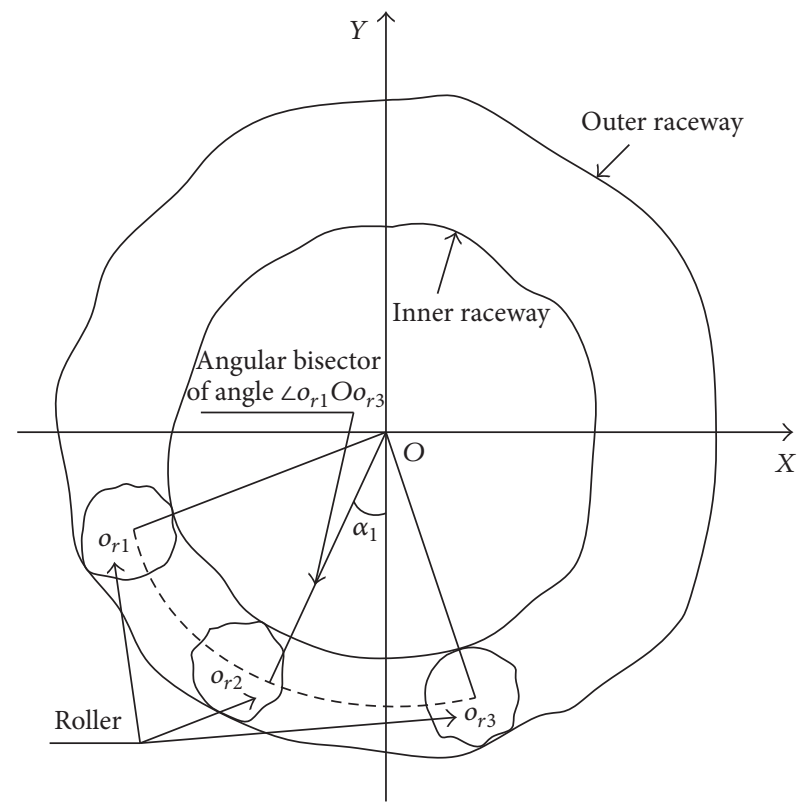

(b) The second contact status of the inner raceway

FIGURE 4: Contact status of the inner raceway.

TABLE 1: Main parameters of cylindrical roller bearing.

\begin{tabular}{lc}
\hline Parameters & Value \\
\hline Inner raceway diameter $(\mathrm{mm})$ & 54.991 \\
Outer raceway diameter $(\mathrm{mm})$ & 75.032 \\
Roller diameter $(\mathrm{mm})$ & 10 \\
Number of roller & 14 \\
\hline
\end{tabular}

error in the inner raceway, the outer raceway, and rollers. Due to the existence of radial internal clearance, the inner raceway only contacts with two nethermost rollers while the bearing is not loaded, as indicated in Figure 5. When the inner raceway, the outer raceway, and rollers are without geometric error, the analysis algorithm for the radial runout of inner ring is derived as follows.

The inner ring rotates an angle $\alpha$; the geometric relationship among bearing components is shown in Figure 5. According to the geometric relationship, (17) are obtained.

$$
\begin{aligned}
& o_{r 1} o_{i}=\sqrt{\left(X_{i}-X_{r 1}\right)^{2}+\left(Y_{i}-Y_{r 1}\right)^{2}}=\frac{\left(d_{i}+D_{w}\right)}{2}, \\
& o_{r 2} o_{i}=\sqrt{\left(X_{i}-X_{r 2}\right)^{2}+\left(Y_{i}-Y_{r 2}\right)^{2}}=\frac{\left(d_{i}+D_{w}\right)}{2},
\end{aligned}
$$

where $X_{r 1}, Y_{r 1}, X_{r 2}$, and $Y_{r 2}$ are the coordinates of the center of two nethermost rollers, $X_{r 1}=0.5\left(d_{e}-D_{w}\right) \cos \beta_{1}$, $Y_{r 1}=0.5\left(d_{e}-D_{w}\right) \sin \beta_{1}, X_{r 2}=0.5\left(d_{e}-D_{w}\right) \cos \beta_{2}$,

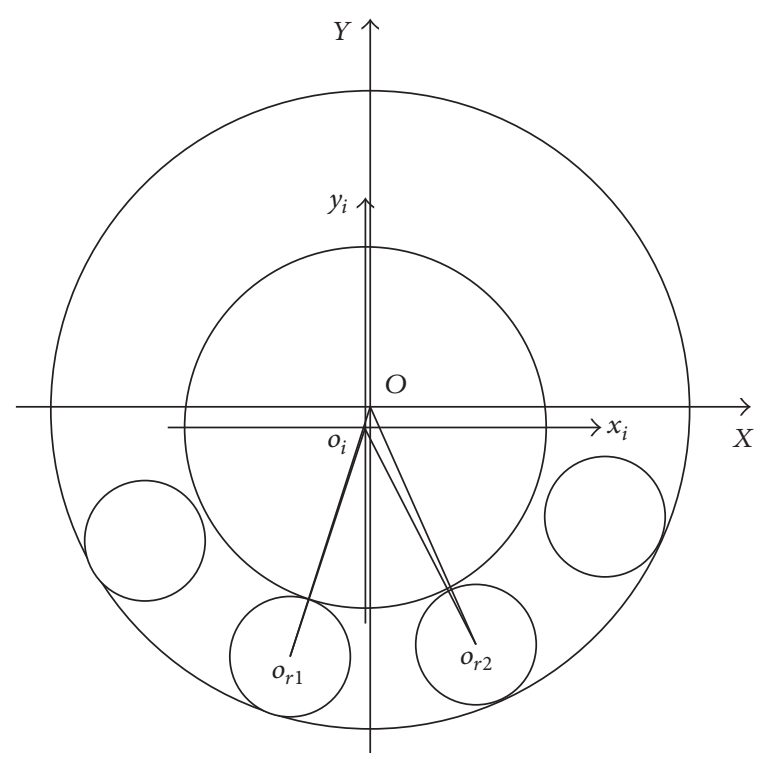

FIGURE 5: Geometric relationship among bearing components without geometric error.

and $Y_{r 2}=0.5\left(d_{e}-D_{w}\right) \sin \beta_{2}$; hereinto, $\beta_{1}, \beta_{2}$ are the position angle of rollers.

The analysis algorithm for the radial runout of inner ring is composed of (17). Equations (17) are simultaneous nonlinear equations with unknown $X_{i}$ and $Y_{i}$. They may be solved by Newton-Raphson method. Having obtained $X_{i}$ and 


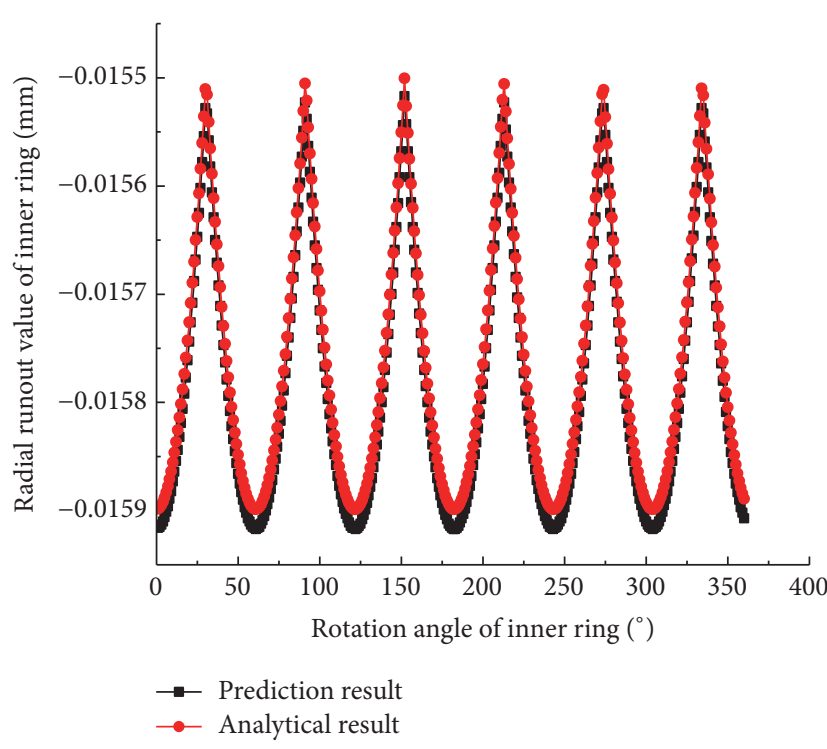

(a) Radial internal clearance for $0.031 \mathrm{~mm}$

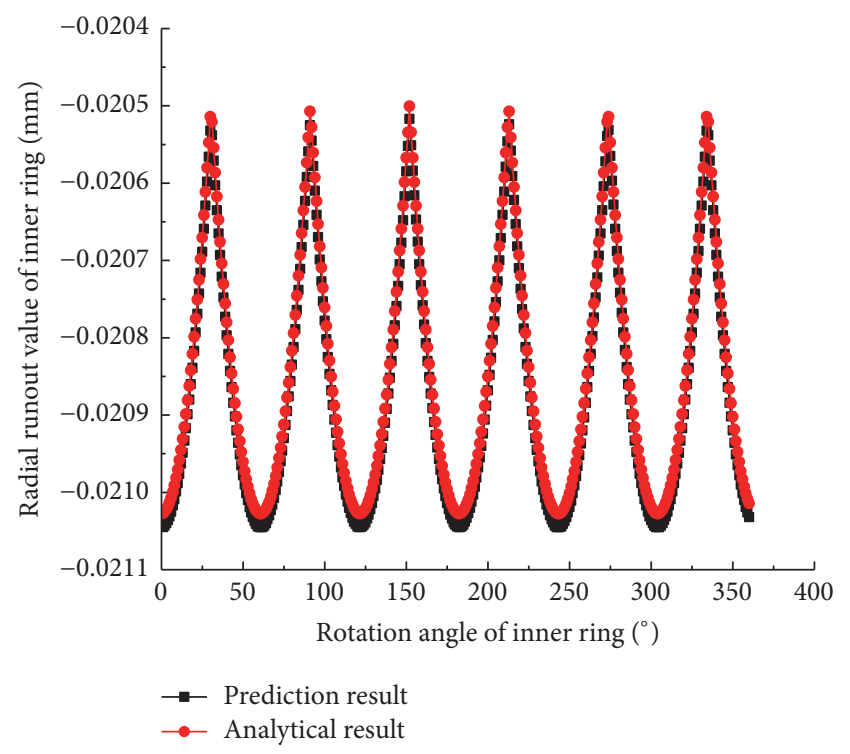

(b) Radial internal clearance for $0.041 \mathrm{~mm}$

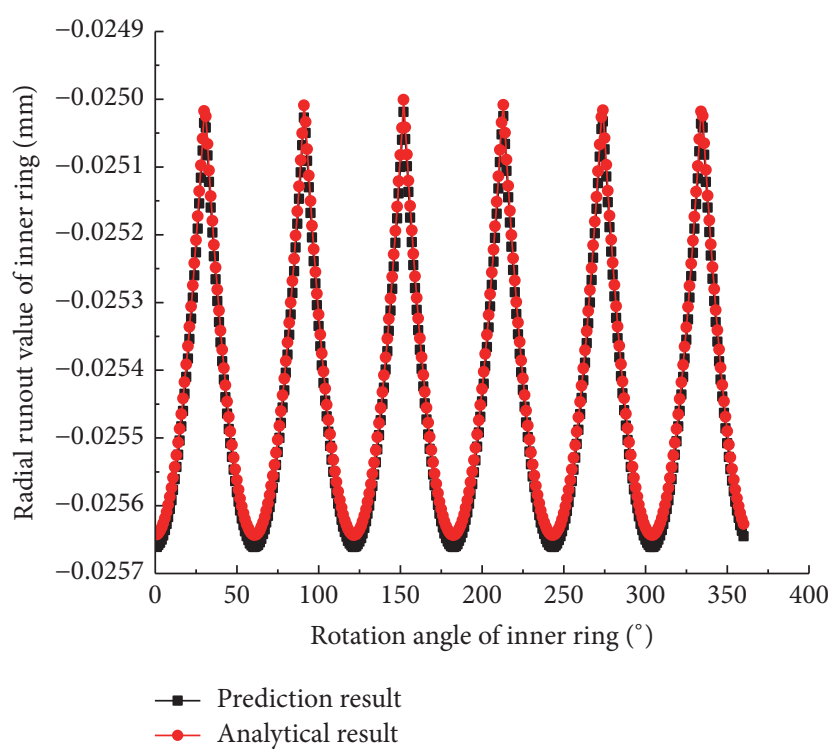

(c) Radial internal clearance for $0.05 \mathrm{~mm}$

FIGURE 6: Comparison between prediction results and analytical results.

$Y_{i}$, the radial runout value of inner ring is obtained when the inner ring rotates an angel $\alpha$.

6.1.2. Verification of the Proposed Prediction Method. The correctness of the proposed prediction method for the radial runout of inner ring is validated via the analytical results obtained from the above analysis algorithm. According to the standard of rolling bearings-radial internal clearance, the radial internal clearance of cylindrical roller bearings with code NU209 varies in the range of $0.03 \sim 0.05 \mathrm{~mm}$. Therefore, the radial internal clearances of $0.031 \mathrm{~mm}, 0.041 \mathrm{~mm}$, and $0.05 \mathrm{~mm}$ are used to calculate the radial runout value of inner ring by the proposed prediction method and analytical algorithm, respectively. The inner ring rotates one revolution; the prediction results and the analytical results are shown in Figure 6. Comparing prediction results with analytical results, the biggest relative error is $0.097 \%$.

\subsection{Verification of the Prediction Method with Inner Raceway Profile for Ellipse}

6.2.1. Analysis Algorithm for the Radial Runout of Inner Ring with Inner Raceway Profile for Ellipse. The profile of the inner raceway is ellipse, and profiles of other bearing components 


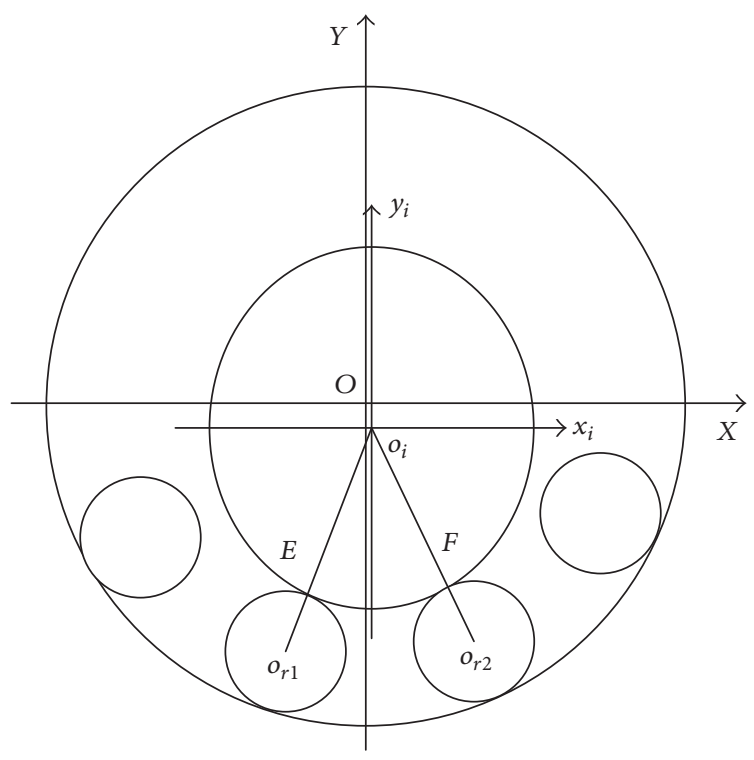

FIGURE 7: Geometric relationship among bearing components with inner raceway profile for ellipse.

are circle. When the ellipticity in the inner raceway is less, the inner raceway only contacts with two nethermost rollers, as shown in Figure 7. When the profile of the inner raceway is ellipse, the analysis algorithm for the radial runout of inner ring is derived as follows.

The inner ring rotates an angle $\alpha$; the geometric relationship among bearing components is shown in Figure 7. According to the geometric relationship, (18) and (19) are obtained.

$$
\begin{aligned}
& o_{r 1} o_{i}=\sqrt{\left(X_{i}-X_{r 1}\right)^{2}+\left(Y_{i}-Y_{r 1}\right)^{2}}=E o_{i}+\frac{D_{w}}{2}, \\
& o_{r 2} o_{i}=\sqrt{\left(X_{i}-X_{r 2}\right)^{2}+\left(Y_{i}-Y_{r 2}\right)^{2}}=F o_{i}+\frac{D_{w}}{2},
\end{aligned}
$$

where $E o_{i}$ is the radius of $E$ point on the inner raceway, which is calculated by (20). $\mathrm{Fo}_{i}$ is the radius of $F$ point on the inner raceway, which is calculated by (21).

$$
\begin{aligned}
& E o_{i}=\frac{a b}{\sqrt{\left(a \cos \left(\theta_{E}-\alpha\right)\right)^{2}+\left(b \sin \left(\theta_{E}-\alpha\right)\right)^{2}}}, \\
& F o_{i}=\frac{a b}{\sqrt{\left(a \cos \left(\theta_{F}-\alpha\right)\right)^{2}+\left(b \sin \left(\theta_{F}-\alpha\right)\right)^{2}}},
\end{aligned}
$$

where $a$ and $b$ are semimajor and semiminor axis of ellipse, respectively. $\theta_{E}$ is the polar angle of point $E$ on the inner raceway, $\theta_{E}=\pi+\arctan \left(\left(Y_{i}-Y_{r 1}\right) /\left(X_{i}-X_{r 1}\right)\right) . \theta_{F}$ is the polar angle of point $F$ on the inner raceway, $\theta_{F}=2 \pi+\arctan \left(\left(Y_{i}-\right.\right.$ $\left.\left.Y_{r 2}\right) /\left(X_{i}-X_{r 2}\right)\right)$.

The analysis algorithm for the radial runout of inner ring is composed of (18) and (21). Equations (18) through (21) are simultaneous nonlinear equations with unknown $X_{i}$ and $Y_{i}$. They may be solved by Newton-Raphson method. Having obtained $X_{i}$ and $Y_{i}$, the radial runout value of inner ring is obtained when the inner ring rotates an angel $\alpha$.
6.2.2. Verification of the Proposed Prediction Method. To verify the correctness of the proposed prediction method for the radial runout of inner ring, different ellipticity in the inner raceway is selected. The semimajor axis of ellipse is $27.4955 \mathrm{~mm}$, and semiminor axis of ellipse is $27.4905 \mathrm{~mm}$, $27.492 \mathrm{~mm}$, and $27.4935 \mathrm{~mm}$ which are used to calculate the radial runout value of inner ring by the proposed prediction method and analysis algorithm, respectively. The inner ring rotates one revolution; the prediction results and the analytical results for the radial runout value of inner ring are shown in Figure 8. Comparing prediction results with analytical results, the biggest relative error is $0.15 \%$. The relative error with inner raceway profile for ellipse is larger than that with inner raceway profile for circle. This is due to the assumption that the curvature center of ellipse is approximate to geometric center of ellipse, which results in the error of the analysis algorithm with inner raceway profile for ellipse.

Regarding Figures 7 and 8 results from this study, the validity of the proposed prediction method is proven by analytical results. The proposed prediction method can accurately forecast the radial runout of inner ring.

\section{Simulation Examples}

Taking NU209 type cylindrical roller bearing as an example, as shown in Table 1, numerical examples are provided to verify the universality of the proposed prediction method.

Figure 9 shows the radial runout value of inner ring when the inner ring rotates 540 degrees; hereinto, the amplitude of roundness error in the inner raceway is $1 \mu \mathrm{m}$, and the harmonic order of roundness error is 10 . The maximal radial runout value of inner ring is $0.0217 \mathrm{~mm}$, and the minimal radial runout value of outer ring is $0.01956 \mathrm{~mm}$. The radial runout of inner ring is $2.14 \mu \mathrm{m}$. 


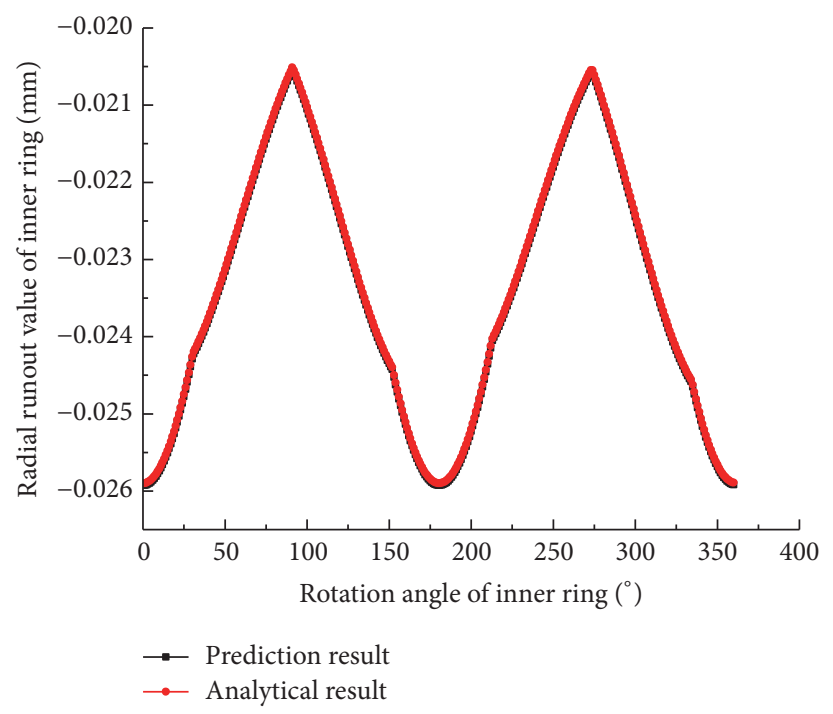

(a) Semiminor axis for $27.4905 \mathrm{~mm}$

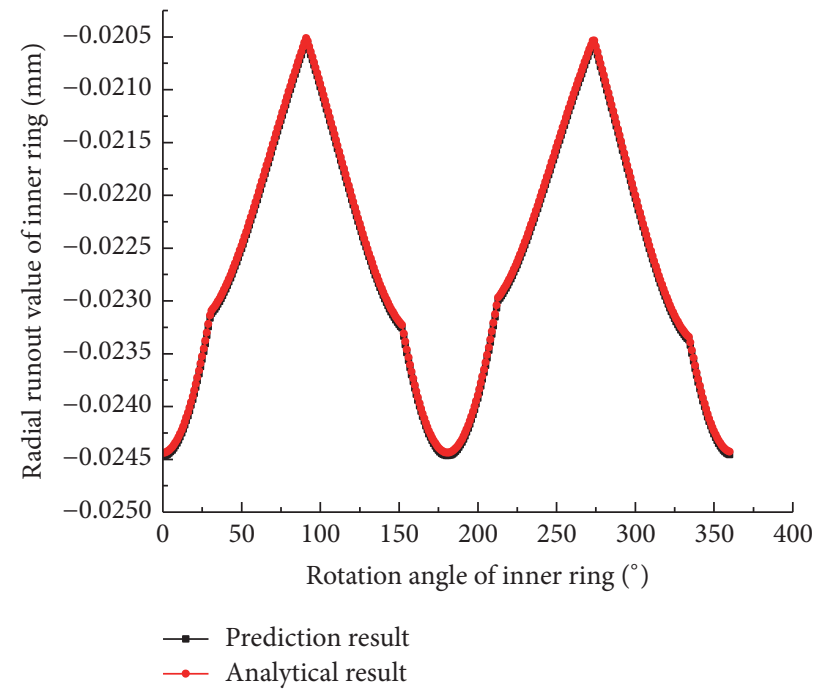

(b) Semiminor axis for $27.492 \mathrm{~mm}$

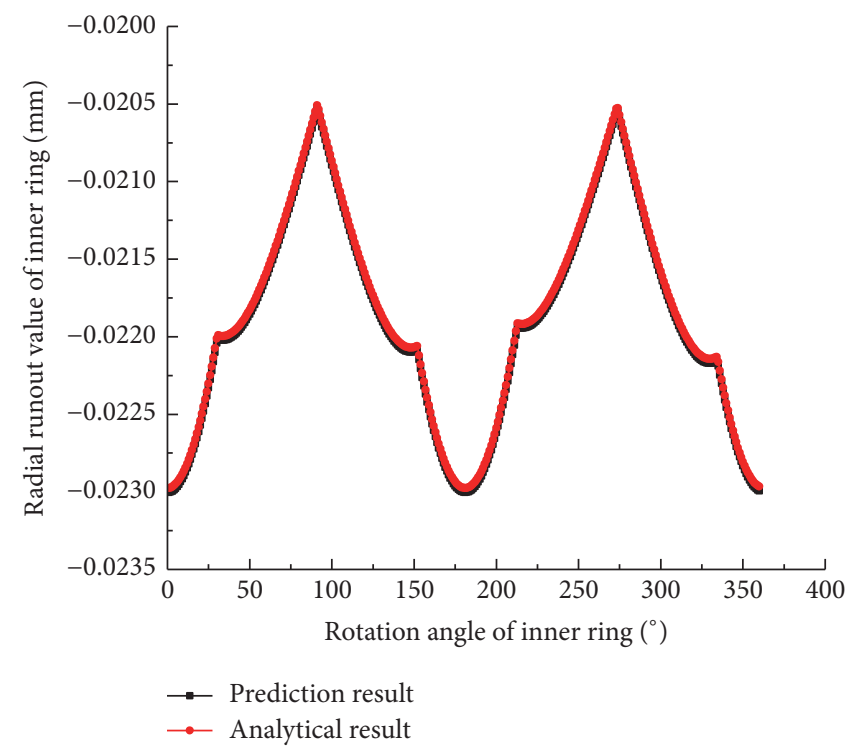

(c) Semiminor axis for $27.4935 \mathrm{~mm}$

FIGURE 8: Comparison between prediction results and analytical results.

Figure 10 shows radial runout value of inner ring when the inner ring rotates 540 degrees; hereinto, the amplitude of roundness error in the outer raceway is $1 \mu \mathrm{m}$, and the harmonic order of roundness error is 12 . The maximal radial runout value of inner ring is $0.02013 \mathrm{~mm}$, and the minimal radial runout value of inner ring is $0.02157 \mathrm{~mm}$. The radial runout of inner ring is $1.44 \mu \mathrm{m}$.

Figure 11 shows radial runout value of inner ring when the inner ring rotates 540 degrees; hereinto, the amplitude of roundness error in all rollers is $0.5 \mu \mathrm{m}$, and the harmonic order of roundness error is 8 . The maximal radial runout value of inner ring is $0.02153 \mathrm{~mm}$, and the minimal radial runout value of inner ring is $0.01956 \mathrm{~mm}$. The radial runout of inner ring is $1.98 \mu \mathrm{m}$.
Figure 12 shows radial runout value of inner ring when the inner ring rotates 540 degrees; hereinto, the amplitudes of roundness error in all rollers, the inner raceway, and the outer raceway are $0.5 \mu \mathrm{m}, 1 \mu \mathrm{m}$, and $1 \mu \mathrm{m}$, respectively, and the harmonic orders of roundness error in all rollers, the inner raceway, and the outer raceway are 15,8 , and 18 , respectively. The dimension errors in all rollers, the inner raceway, and the outer raceway are $1 \mu \mathrm{m}$. The maximal radial runout value of inner ring is $0.02186 \mathrm{~mm}$, and the minimal radial runout value of inner ring is $0.01668 \mathrm{~mm}$. The radial runout of inner ring is $5.186 \mu \mathrm{m}$.

The radial runout values of inner ring are calculated by the proposed prediction method when there are roundness errors in the inner raceway, the outer raceway, and the 


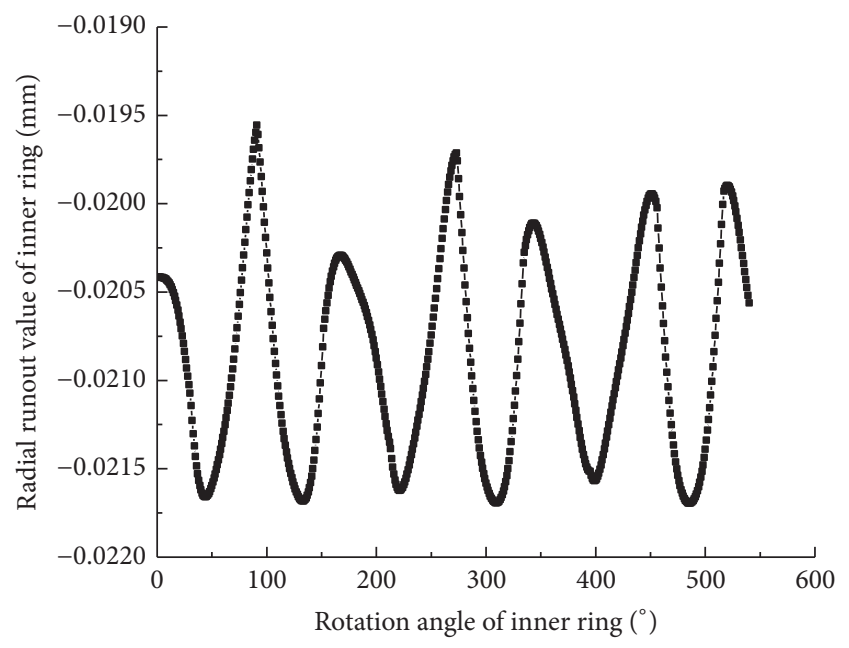

FIgURE 9: Radial runout value of inner ring.

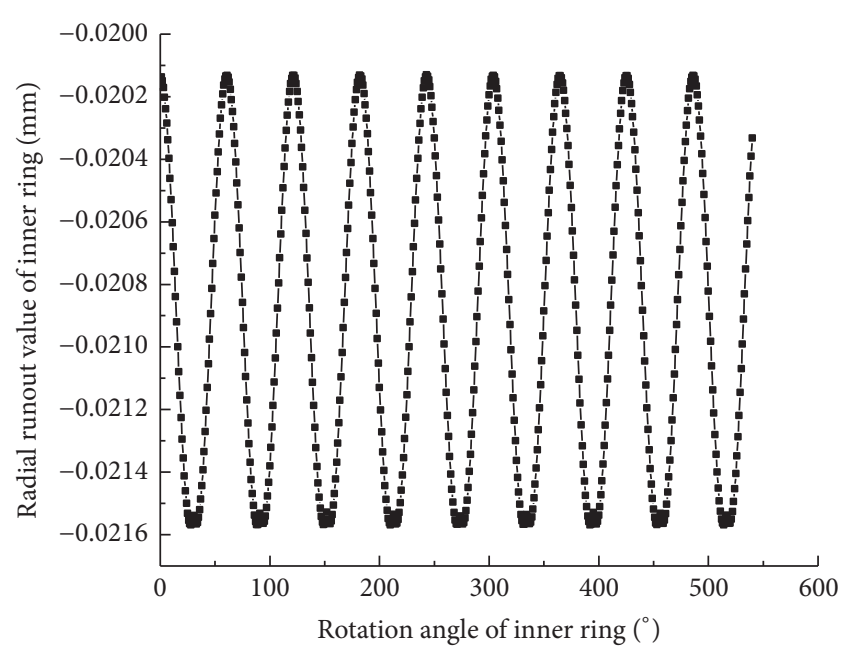

FIgURE 10: Radial runout value of inner ring.

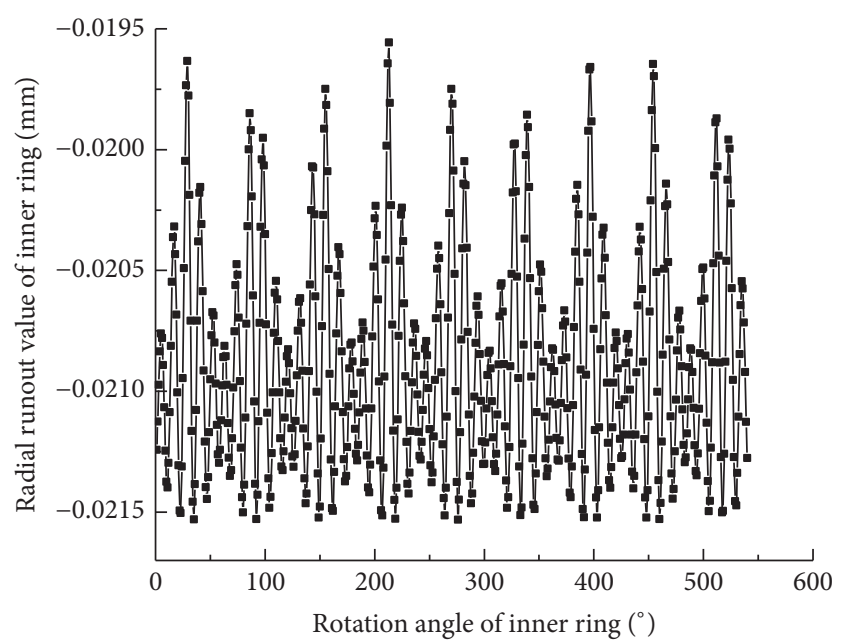

Figure 11: Radial runout value of inner ring.

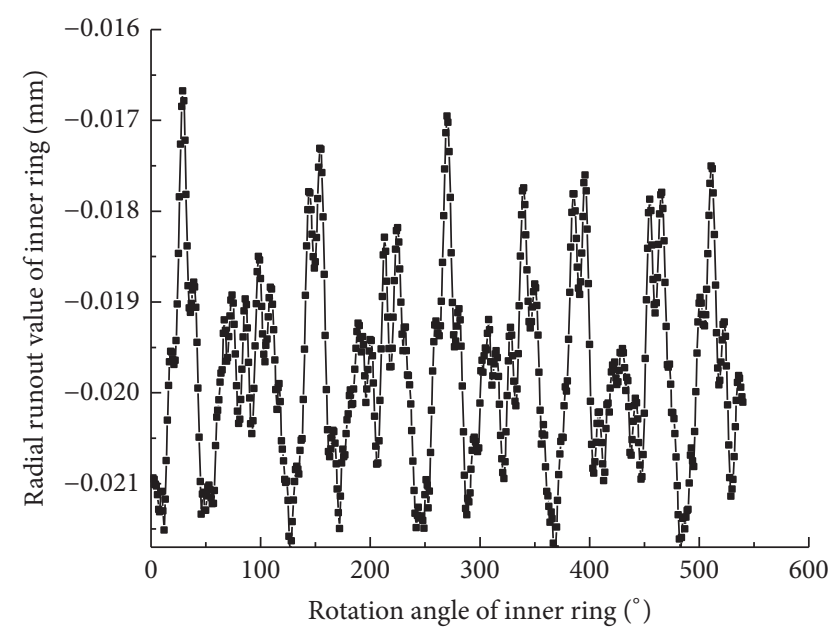

FIgURE 12: Radial runout value of inner ring.

rollers. The universality of the proposed prediction method is verified by numerical examples. Therefore, the proposed prediction method can predict the radial runout of inner ring with random dimension and roundness errors in the inner raceway, outer raceway, and rollers.

\section{Conclusions}

A prediction method for the radial runout of inner ring in cylindrical roller bearings is presented in this paper. The correctness of the proposed prediction method is validated via two particular cases that the inner raceway shapes are circle and ellipse. Two analytical results of particular cases for the radial runout value of inner ring are derived, and the results show great coincidence with the prediction results obtained from the proposed prediction method. Numerical examples are provided to verify the universality of the proposed prediction method. This method can predict the radial runout of inner ring after bearing components with dimension and form errors are assembled. Based on the proposed prediction method, the coupling effect of the roller number and roundness errors in the inner raceway, the outer raceway, and rollers on rotational accuracy of assembled bearing can be investigated efficiently. Furthermore, the relationship between harmonic order of roundness error and the roller number which has a great effect on the radial runout of inner ring is established, which may provide the theoretical basis for the precision design and the control of machining process parameters of bearing components.

\section{Conflicts of Interest}

The authors declare that they have no conflicts of interest.

\section{Acknowledgments}

The authors gratefully thank the National Natural Science Foundation of China (no. 51375148), the Natural Science Foundation of Henan Province of China (no. 162300410064), 
and the Project of Basic and Advanced Technology Research of Henan Province of China (no. 142300413217) for financial support. This work is also supported by the Key Research Program of the Higher Education Institutions of Henan Province (no. 15A460022) and the Program for Innovative Research Team (in Science and Technology) in University of Henan Province (no. 15IRTSTHN008).

\section{References}

[1] L. Wang, L. Cui, D. Zheng, and L. Gu, "Nonlinear dynamics behaviors of a rotor roller bearing system with radial clearances and waviness considered," Chinese Journal of Aeronautics, vol. 21, no. 1, pp. 86-96, 2008.

[2] L. Xu, Y. Li, C. Li, and Y. Yang, "Effects of bearing clearance and flexibility on the dynamic errors of mechanisms," Journal of Mechanical Engineering, vol. 48, no. 7, pp. 30-36, 2012.

[3] J. Okamoto, T. Ohmori, and T. Kitahara, "Study on run-out of ball bearings: relation between unroundness of race and locus of shaft in rotation," Japanese Journal of Tribology, vol. 46, no. 7, pp. 578-584, 2001.

[4] S. Noguchi and K. Ono, "Reduction of NRRO in ball bearings for HDD spindle motors," Precision Engineering, vol. 28, no. 4, pp. 409-418, 2004.

[5] S. Noguchi, K. Hiruma, H. Kawa, and T. Kanada, "The Influence of location of balls and ball diameter difference in rolling bearings on the nonrepetitive runout (NRRO) of retainer revolution," Precision Engineering, vol. 29, no. 1, pp. 11-18, 2005.

[6] S. Noguchi, K. Tanaka, and K. Ono, "Theoretical analysis of a ball bearing used in HDD spindle motors for reduction of NRRO," IEEE Transactions on Magnetics, vol. 35, no. 2, pp. 845850, 1999.

[7] S. Noguchi and K. Hiruma, "Theoretical analysis of the NRRO of the components of retainer rotation in consideration of diameter difference and disposition of balls in a ball bearing," Japanese Journal of Tribology, vol. 48, no. 2, pp. 167-176, 2003.

[8] S. Tada, "Three-dimensional analysis of non-repeatable runout (NRRO) in ball bearing," KOYO Engineering Journal, pp. 31-37, 2002.

[9] G. H. Jang, D. K. Kim, and J. H. Han, "Characterization of NRRO in a HDD spindle system due to ball bearing excitation," IEEE Transactions on Magnetics, vol. 37, no. 2 I, pp. 815-819, 2001.

[10] Z. Yang, J. Hong, J. Liu, Y. Ding, and M. Y. Wang, “Theoretical method to reduce the non-repetitive run-out (NRRO) of angular contact ball bearings," in Proceedings of 2011 IEEE International Symposium on Assembly and Manufacturing (ISAM '11), pp. 125-130, Tampere, Finland, 2011.

[11] Z. Yang, H. Jun, and J. Zhang, "A new method to analyze threedimensional non-repetitive runout(3D-NRRO) of angular contact ball bearings," in Proceedings of the ASME 2011 international mechanical engineering congress exposition, Denver, CO, USA, 2011.

[12] Z. Yang, J. Hong, J. Liu, and Y. Zhu, "Theoretical model to analyze the non-repetitive run-out (NRRO) of ball bearings," Advanced Science Letters, vol. 4, no. 6-7, pp. 2522-2527, 2011.

[13] G. Chen, B. Wang, and F. Mao, "Effects of raceway roundness and roller diameter errors on clearance and runout of a cylindrical roller bearing," Proceedings of the Institution of Mechanical Engineers, Part J: Journal of Engineering Tribology, vol. 227, no. 3, pp. 275-285, 2013.
[14] G. Chen, F. Mao, and B. Wang, "Effects of off-sized cylindrical rollers on the static load distribution in a cylinder roller bearing," Proceedings of the Institution of Mechanical Engineers, Part J: Journal of Engineering Tribology, vol. 226, no. 8, pp. 687696, 2012.

[15] J. Liu, J. Hong, Z. Yang, Y. Zhu, and X. Li, "Running accuracy of high speed precision angular contact ball bearings," Journal of Xian Jiaotong University, vol. 45, no. 11, pp. 72-78, 2011.

[16] C. Li and F. Mao, "The impact of geometrical errors of deep-groove ball bearings on non-repetitive run-out," in Modular Machine Tool \& Automatic Manufacturing Technique, vol. 1, p. 13, 9, 2013.

[17] C. P. Bhateja and R. D. Pine, "Rotational accuracy characteristics of the preloaded hollow roller bearing," Journal of Lubrication Technology, vol. 103, no. 1, pp. 6-12, 1981.

[18] B. Wang, Effect of Geometric Error of Elements on Mechanical Performance in Cylindrical Roller Bearing, Dalian University of Technology, 2013.

[19] F. Song, J. Li, and Y. Liu, "Influence of raceway roundness error on running accuracy of cylindrical roller bearings," Bearing, vol. 05, pp. 1-4, 2011.

[20] W. Shi, J. Li, and Y. Liu, "Forecast and simulation of rotational accuracy of cylindrical roller bearing," Mechanical Science and Technology for Aerospace Engineering, vol. 45, pp. 72-78, 2011.

[21] Y. Liu, J. S. Li, W. X. Sh, and X. Jia, "An algorithm to prediction the radial runout of cylindrical roller bearings", Applied Mechanics and Materials, vol. 80-81, pp. 551-555, 2011. 


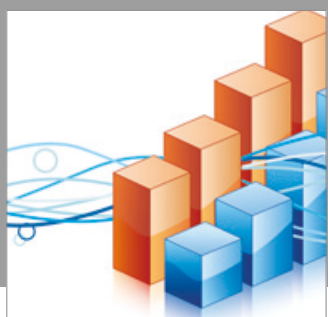

Advances in

Operations Research

vatersals

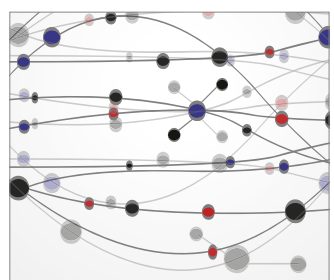

\section{The Scientific} World Journal
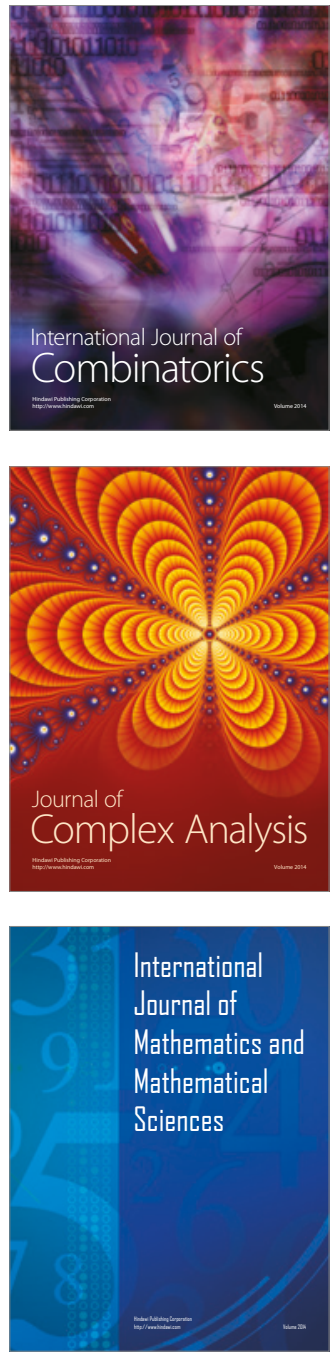
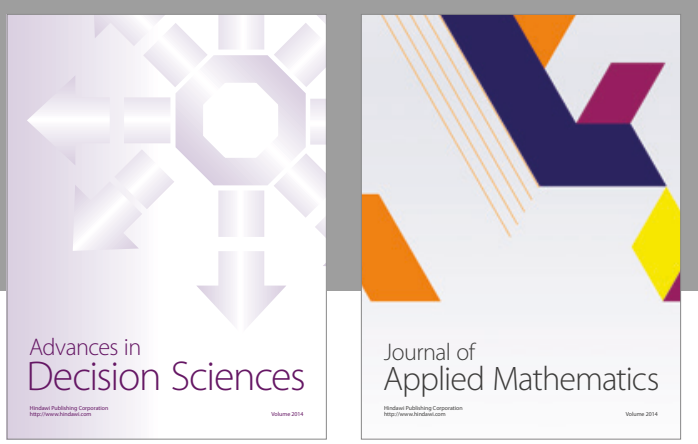

Algebra

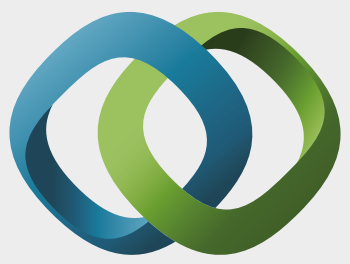

\section{Hindawi}

Submit your manuscripts at

https://www.hindawi.com
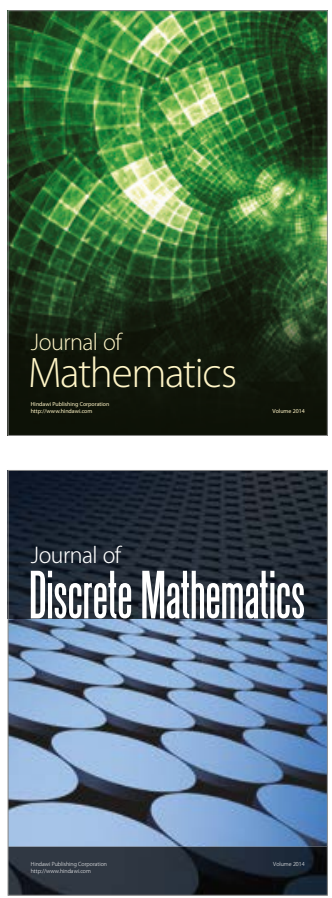

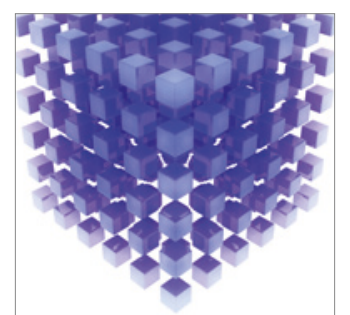

Mathematical Problems in Engineering
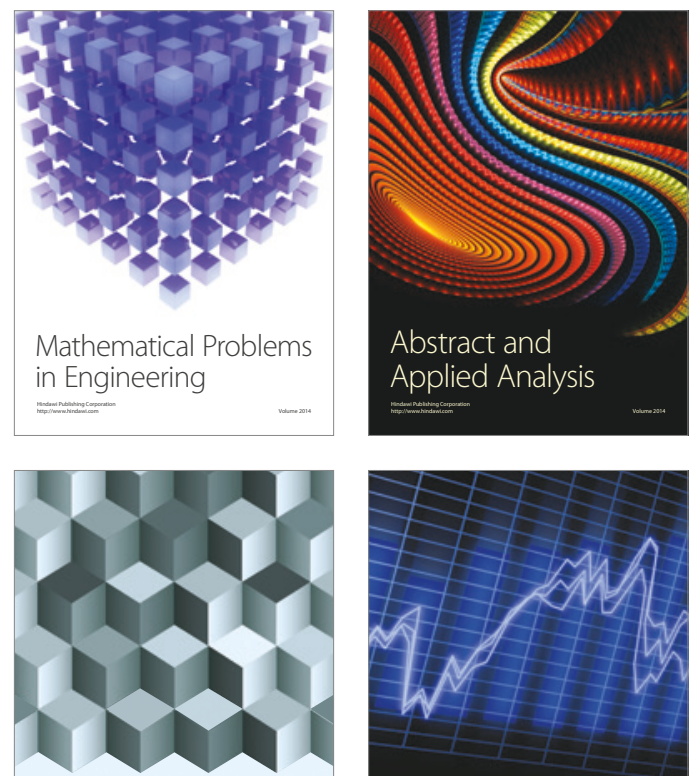

Journal of

Function Spaces

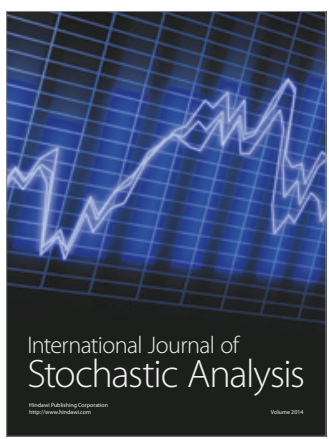

Probability and Statistics
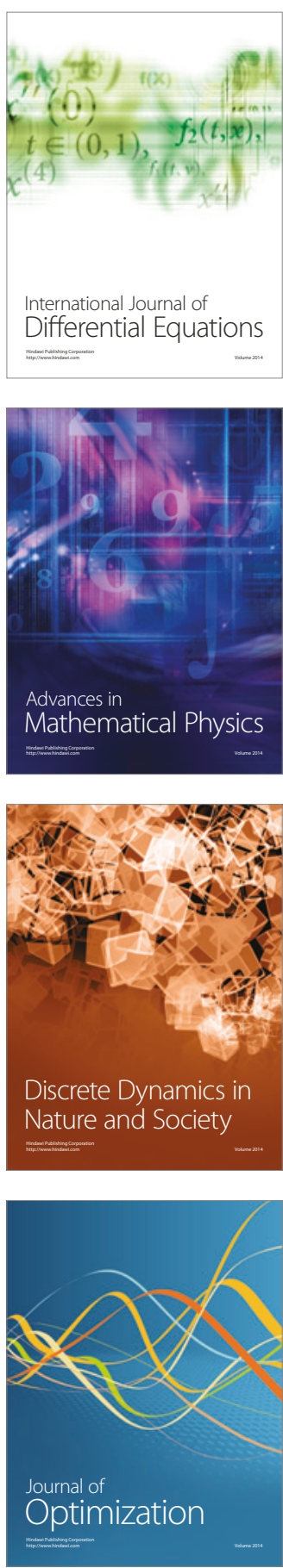